\title{
EXHAUST SIMULATION TESTING OF A HYPERSONIC AIRBREATHING MODEL AT TRANSONIC SPEEDS
}

\author{
Lawrence D. Huebner* \\ David W. Witte ${ }^{\dagger}$ \\ NASA Langley Research Center \\ Hampton, VA \\ Earl H. Andrews, Jr. \\ Swales Aerospace \\ Hampton, VA
}

\begin{abstract}
An experimental study was performed to examine jet-effects for an airframe-integrated, scramjet-rocket combined-cycle vehicle configuration at transonic test conditions. This investigation was performed by testing an existing exhaust simulation wind tunnel model, known as Model 5B, in the NASA Langley 16-Ft. Transonic Tunnel. Tests were conducted at freestream Mach numbers from 0.7 to 1.2, at angles of attack from -2 to +14 degrees, and at up to seven nozzle static pressure ratio values for a set of horizontal-tail and body-flap deflections. The model aftbody, horizontal tails, and body flaps were extensively pressure instrumented to provide an understanding of jet-effects and control-surface/plume interactions, as well as for the development of analytical methodologies and calibration of computational fluid dynamic codes to predict this type of flow phenomenon. At all transonic test conditions examined, the exhaust flow at the exit of the internal nozzle was over-expanded, generating an exhaust plume that turned toward the aftbody. Pressure contour plots for the aftbody of Model 5B are presented for freestream transonic Mach numbers of 0.70, 0.95, and 1.20. These pressure data, along with shadowgraph images, indicated the impingement of an internal plume shock and at least one reflected shock onto the aftbody for all transonic conditions tested. These results also provided evidence of the highly three-dimensional nature of the aftbody exhaust flowfield. Parametric testing showed that angle-of-attack, static nozzle pressure ratio, and freestream Mach number all affected the exhaust-plume size, exhaust-flowfield shock structure, and the aftbody-pressure distribution, with Mach number having the largest effect. Integration of the aftbody pressure data showed large variations in the pitching moment throughout the transonic regime.
\end{abstract}

\section{NOMENCLATURE}

CTE cowl trailing edge

HAPB Hypersonic Airbreathing Propulsion Branch

jet-off Simulant exhaust jet turned off

jet-on Simulant exhaust jet turned on

M Mach number

NASP National Aero-Space Plane

P Static pressure

PAI Propulsion Airframe Integration

SNPR Static Nozzle Pressure Ratio $=\mathrm{P}_{4} / \mathrm{P}_{\infty}$

16-Ft. TT NASA Langley 16-Ft. Transonic Tunnel

$\alpha \quad$ Angle of attack

$\gamma \quad$ Ratio of specific heats

\section{Subscripts}

$4 \quad$ Station 4, cowl exit plane station

$\infty \quad$ Freestream condition

*Associate Fellow, Aerospace Engineer, HAPB

${ }^{\dagger}$ Member, Aerospace Engineer, HAPB

${ }^{\ddagger}$ Associate Fellow, Aerospace Engineer, assigned to

Hyper-X Program Office

\section{INTRODUCTION}

NASA is conducting research in the area of hypersonic airbreathing vehicle design by developing a series of experimental aircraft identified as X-43A, X-43B, X-43C, and X-43D ${ }^{1}$. These flight research aircraft utilize scramjet engines that require a high degree of integration of this propulsion system with the airframe. This is referred to as propulsion airframe integration (PAI). The primary PAI issues for an airframe-integrated. scramjet-powered aircraft (Fig. 1) are the forebody-inlet interactions, the exhaust-jet interactions with the external nozzle and the control surfaces of the aftbody, and interactions of the propulsion-control system with the vehicle-control system. This paper focuses just on the examination of the exhaust-jet interactions with the external nozzle and control surfaces of an airframe-integrated scramjetrocket combined-cycle aircraft at transonic flight conditions where the propulsion system within the flowpath is operated in the rocket mode. The motivation for this jet-effects test is the fact that future operational aircraft that include hypersonic airbreathing propulsion will have to fly through the transonic speed 
regime and that the physics associated with this type of flow are not well understood.

For a hypersonic airbreathing vehicle, the nozzle exhaust flow is highly overexpanded at transonic speeds because the freestream pressure is much greater than it is at the hypersonic design condition. A strong interest developed to acquire a transonic jet-effects experimental data set for computational comparison because of the uncertainty associated with analytical and computational predictions with respect to if, and where, internal plume-shock impingement and flow separation occurs. An exhaust-simulation wind-tunnel model, known as Model 5B, was identified as the best candidate test model for this effort, because it was an existing model of an airframe-integrated scramjet aircraft known as the National Aero-Space Plane (NASP) that contained configurational features still being proposed by NASA. Model 5B, which is approximately 30 inches in length, was designed to measure jet-effects and nozzle-surface performance increments, using exhaust simulation, for tests in supersonic and hypersonic aerodynamic wind tunnels.

To acquire an experimental jet-effects dataset at transonic flight conditions, Model 5B was tested in the NASA Langley 16-Foot Transonic Tunnel (16-Ft. TT) in early 2002 . The primary objective of this $16-\mathrm{Ft}$. TT Model 5B test was to determine the pressures on the aftbody lower surface (external nozzle) for poweredsimulation conditions at transonic speeds. A secondary objective of the 16-Ft. TT Model 5B test was to measure jet-effects on the vehicle control surfaces in this speed regime.

\section{APPARATUS AND PROCEDURES}

\section{Test Facility Description}

The Langley 16-Foot Transonic Tunnel is a closed circuit, single return, continuous flow, atmospheric tunnel that uses air as the test medium ${ }^{2}$. The normal testing range consists of freesteam Mach numbers $\left(\mathrm{M}_{\infty}\right)$ from 0.2 to 1.25 , angles of attack $(\alpha)$ from $-10^{\circ}$ to $+25^{\circ}$, roll angles from $-90^{\circ}$ to $+90^{\circ}$, total temperatures from ambient to $175^{\circ} \mathrm{F}$, static pressures from 4.86 psi to atmospheric, dynamic pressure up to $900 \mathrm{psf}$, and Reynolds numbers up to $4.4 \times 10^{6} / \mathrm{ft}$. An auxiliary $1800-$ psi air system is also available for jet simulation, capable of mass flow rates up to $15 \mathrm{lbm} / \mathrm{sec}$. Speeds up to Mach 1.05 are obtained with the tunnel main-drive fans, and speeds above Mach 1.05 are obtained with the combination of the main-drive fans and test-section plenum suction.

\section{Model Description}

An installation image of Model 5B in the 16-Ft. TT is presented in Fig. 2. Fig. 3 shows a profile schematic illustration of Model 5B revealing all of its major internal features utilized during this test. The model was mounted to the facility by a strut-sting combination attached to the forebody upper surface. The strut also provided the delivery passage for the simulant exhaust gas to the model and a cavity for routing instrumentation. The simulant exhaust gas was delivered into a plenum within the model forebody (yellow region in Fig. 3) and then expanded through an internal supersonic nozzle, designed to simulate the target exit Mach number for the NASP engine at a specified flight condition. Five internal nozzles were designed and built for Model 5B during the NASP program. These internal nozzles for Model 5B were pressure-instrumented as indicated in Fig. 3. For cost effectiveness in the 16-Ft. TT, air was used as the simulant exhaust gas. Model 5B utilized a faired-over inlet, which was designed to direct the flow around the inlet with minimal impact on aftbody flow structure compared to a flowing inlet ${ }^{3}$. Model 5B incorporated a pressure-instrumented aftbody with 188 pressure taps on the external nozzle surface to enable determination of the pressure distribution on the external nozzle surface. Model 5B also had pressure-instrumented horizontal tails and body flaps for examination of the exhaust-jet effect on these control surfaces. The location of these pressure taps is shown in Fig. 4. The cowl external surface was also pressure-instrumented for measurement of any exhaust-jet effect on this surface.

\section{Model 5B Simulation of the Exhaust Flowfield}

With this test technique ${ }^{4}$, four key parameters need to be appropriately reproduced in order to accomplish the correct force and moment simulation of an exhaust flowfield. These parameters are geometric similarity for the internal and external nozzles, the internal nozzle exit Mach number $\left(\mathrm{M}_{4}\right)$, the static nozzle pressure ratio - defined as the internal nozzle exit static pressure divided by the freestream static pressure $\left(\mathrm{SNPR}=\mathrm{P}_{4} / \mathrm{P}_{\infty}\right)$, and the ratio of specific heats $(\gamma)$ for the exhaust gas throughout the entire expansion. Essentially, Mach number and $\gamma$ determine the expansion characteristics for any nozzle flow, thereby generating the requirement for a match of $\mathrm{M}_{4}$ and $\gamma$. The correct reproduction of the exhaust plume boundary is accomplished by matching the correct SNPR. This exhaust-plume boundary constitutes the virtual lower surface geometry for the external nozzle.

In terms of nozzle geometric similarity, Model 5B has an aftbody that consists of a single expansion ramp nozzle that is comparatively longer than some aftbodies proposed for future vehicles. The nozzle plenum for Model 5B was designed for a maximum pressure of 250 psia, which limited the range of SNPR simulation that 
could be obtained with the internal nozzle used during 16-Ft. TT testing. The set of target SNPR values prescribed prior to testing is presented in Fig. 5. All of the target SNPR values in the transonic regime were able to be reproduced by Model 5B in this test, with the exception of the Mach 0.7 test point, which was above the maximum SNPR capable of being tested at Mach 0.7. The internal nozzle selected for this test produced an average exit plane Mach number that was in the middle of the expected cowl-trailing-edge, Machnumber range for transonic flight. Since air, with a $\gamma$ of 1.4, was used as the exhaust simulant, the realistic value of $\gamma$ in the nozzle exhaust flow was not simulated in this test. The expansion characteristics of the rocket exhaust at this speed, with a lower $\gamma$ value, would be somewhat different. However, the primary objectives of the test could still be met because if the analytical and computational methods could predict the correct exhaust flow expansion and jet-effects for a perfect gas, then it should also be able to do the same for a realistic, thermally-perfect exhaust gas.

\section{Test Matrix and Procedures}

The Model 5B test matrix was designed to provide sufficient data for compilation of jet-effects and nozzle performance at transonic speeds. Test parameters are presented in Table 1; however, the data for the runs performed at Mach numbers of 0.98 and 1.05 may be suspect because model blockage is critical this close to sonic conditions.

Table 1. Parameters for Model 5B Test in 16-Ft. TT.

\begin{tabular}{|l|l|}
\hline Angle of Attack (deg) & $-2,0,2,4,6,8,10,12,14$ \\
\hline Angle of Sideslip (deg) & 0 \\
\hline Mach Number & $0.7,0.8,0.9,0.95,0.98,1.05,1.1,1.2$ \\
\hline Reynolds Number & $\sim 4$ million/ft \\
\hline SNPR & 0.2 to 0.7 (see Fig. 5) \\
\hline Wing Deflections (deg) & $0 / 0,5 / 5,-5 /-5,10 / 10,-10 /-10$, no wings \\
\hline Body-Flap Deflections (deg) & $0 / 0,20 / 20,-20 /-20$ \\
\hline
\end{tabular}

For a given model configuration of wings and/or body-flap deflection, a wind-tunnel run was performed by first establishing the tunnel Mach number and setting the SNPR value by controlling the desired internal model plenum pressure while the model was positioned at $\alpha=0^{\circ}$. The model was then stepped through the $\alpha$ schedule shown in Table 1 and ended with a repeat point taken at $\alpha=0^{\circ}$.

\section{Exhaust-Jet Flow Features}

RESULTS AND DISCUSSION

The fundamental features of the overexpanded exhaust flowfield observed in this transonic powered test are shown in the shadowgraph image of Fig. 6. Since the exhaust jet flow is supersonic, several shocks are evident in this image. The interpretation and description of these features are shown in the profile view illustration in Fig. 7a. The overexpanded flow at the cowl trailing edge (CTE) resulted in a plume boundary formation that turned towards the external nozzle surface. This exhaust-plume boundary generated an internal plume shock at the CTE, which impinged on the aftbody surface and then created a reflected shock off the aftbody. This aftbody reflected shock then intersected the external plume boundary (shear layer) creating a lambda shock formation with a reflected plume shock that subsequently impinged farther downstream on the aftbody. In some cases, the overexpansion was large enough to create separated regions on the cowl surface near the CTE and on the aftbody downstream of the internal plume shock. In the planform view of the aftbody (Fig. 7b), the spanwise nature of this flowfield structure is illustrated. The external nozzle surface initially experiences a region (I) of continued nozzle expansion of the exhaust flow. The definition of the end of this region is a function of both the SNPR and the external flow (which is at higher static pressure) propagating toward the model centerline. A region (II) of pressure rise due to internal plume-shock impingement follows this. This region is then followed by a region (III) of prominent pressure rise, due to the impingement of the reflected plume shock onto the aftbody, before flow expansion reduces the aftbody pressure towards the freestream value near the model trailing edge.

\section{Representative Aftbody Pressure Contours}

Aftbody pressure contours and shadowgraph images for three separate transonic Mach numbers for nominal jet-on conditions are shown in Figs. 8-10. These three particular test conditions were representative of typical jet-on trends and, thus, were selected for discussion. In each of the three figures, a pressure contour plot and a shadowgraph image are shown as parts (a) and (b). The fuselage length for both parts is horizontally aligned for direct comparison.

The first set, Fig. 8 , is for $\mathrm{M}_{\infty}=1.2, \mathrm{SNPR}=0.434$, and $\alpha=4^{\circ}$. Internal-nozzle, exhaust-flow expansion occurs on the initial part of the aftbody, as seen in the light blue part of the pressure contour plot of Fig. 8a. Initial pressure rises occur outboard first because of the higher freestream-pressure inflow at the end of the nozzle sidewall, which then propagates inward toward the centerline. Pressure levels in the semispan regions just downstream of the sidewall trailing edge are nearly coincident with the freestream static pressure. The level of peak pressure is highest on the centerline with subsequent decreased peak levels moving outward and downstream. The three-dimensional flow effect is also evident in this pressure contour plot, where, on the centerline, the nozzle-exhaust expansion extends farthest downstream and the peak pressures occur 
farthest upstream. The shadowgraph image, Figure 8b, exhibits the shocks in the jet flow for this test point. With the streamwise alignment of the pressure contours and the shadowgraph image, it is evident that the initial pressure rise is the result of the internal plume shock impinging upon the aftbody. The peak pressures occur in the region of the lambda-shock.

Similar results are evident in Fig. 9 for $\mathrm{M}_{\infty}=0.95$, SNPR $=0.530$, and $\alpha=0^{\circ}$. The data in Fig. 9a indicate the region of continued nozzle expansion followed by an initial pressure rise due to the internal plume shock and then a secondary, more prominent, pressure rise due to the reflected plume shock. The threedimensional nature of the external nozzle surface pressure distribution is also evident in Fig. 9a in that the spanwise pressure variation starts at the trailing edge of the nozzle sidewall and then propagates inboard, due to the higher pressure external flow turning inward into the lower pressure exhaust jet.

Aftbody pressure data for the $\mathbf{M}_{\infty}=0.70$, $\mathrm{SNPR}=0.268$, and $\alpha=0^{\circ}$ test point are presented in Figure 10a. This contour plot reveals a flow structure that is different from the other two conditions just discussed. It shows that the internal nozzle exhaustflow does not expand on the aftbody, since the initial pressure rise has already occurred prior to the first row of pressure taps on the aftbody. Actually, the nozzle flow is separated since the actual nozzle exit pressure was found to be above the theoretical nozzle exit pressure assuming no separation. At this pressure level, the internal nozzle flow on the cowl side, next to the freestream flow, became separated inside the nozzle. This cowl-side separation generated a shock upstream of the cowl trailing edge that impinged on the body side near the nozzle exit and resulted in the initial pressure rise. Three pressure peaks are evident along the length of the aftbody and are the result of three separate reflected plume shocks and appear to be at a location that is fairly constant in the spanwise direction.

\section{SNPR and Angle-of-Attack Effects}

The effects of static nozzle pressure ratio and angle of attack are representatively shown in Fig. 11 and 12. Both sets of six contour plots show the pressure distributions on the lower semispan surface of the aftbody and the lower surface of the horizontal tail as the SNPR is increased from the no-jet condition (part ' $a$ ') to a maximum SNPR value (part 'f') for $\mathrm{M}_{\infty}=0.95$ with undeflected horizontal tails. Fig. 11 presents data at $\alpha=0^{\circ}$, while Fig. 12 presents the pressure data at $\alpha=12^{\circ}$. While actual values are not provided, the range on all contour plots is the same for both figures.
At $\alpha=0^{\circ}$, there are a number of trends that can be seen as SNPR is increased. First, the expansion region from the internal nozzle propagates farther downstream. Second, the location of the large pressure rise moves downstream and extends farther downstream away from the vehicle centerline. The magnitude of this pressure rise also increases with increasing SNPR. Finally, there appears to be no plume influence on the horizontal tail, as seen by the nearly similar pressure contours on all five jet-on contours (Fig. 11b-11f). There does appear to be a small impact when comparing the no-jet to lowest-SNPR cases. This is likely due to the interaction of the jet with the higher-pressure external flow causing a slight pressure rise on the horizontal tail.

At $\alpha=12^{\circ}$ (Fig. 12), the fact that the external flow has a bigger influence on the aftbody pressures is evident. First, the extent of the internal-nozzle expansion is limited to just beyond the sidewall trailing edge, even at the higher SNPR values. Second, the large pressure-rise region has taken a slightly different character than the $\alpha=0^{\circ}$ data. While the peak pressure location on the centerline is consistent, the magnitude is slightly less, and the off-centerline, high-pressure region is actually upstream of the centerline peak. This is because the local flow external to the sidewall is at a higher pressure at the increased angle of attack. Finally, while the pressure levels on the horizontal tails are higher, the similar trend of only a slight pressure rise on the lower surface of the horizontal tail from the jet-off to jet-on data is evident. Furthermore, once the jet is on, no significant change in horizontal tail pressurization is evident as SNPR is increased.

\section{Jet Effects for a Simulated Transonic Trajectory}

Fig. 13 presents aftbody and horizontal-tail pressure contours for six Mach number/SNPR combinations at $\alpha=0^{\circ}$ that simulate a scramjet-rocket, combined-cycle vehicle operating in rocket mode from Mach 0.7 to 1.2. Examination of these data reveals significant differences in the pressure distributions. As the freestream Mach number is increased, the extent of the internal nozzle exhaust flow expansion on the aftbody increases, the peak pressure locations shift downstream, and the number of peaks changes. Large differences in the pressure distributions and range of pressure levels are evident from the cowl trailing edge to the end of the vehicle.

The pressure data for the entire Model 5B aftbody were integrated to yield the aftbody normal force, axial force, and pitching moment for each of these conditions. These results are presented in Fig. 14. They indicate a wide range of loads for the external nozzle surface Model 5B from Mach 0.7 to Mach 1.2, as expected from the pressure data shown in the previous 
figure. In particular, the large variation of pitching moment over this transonic speed regime indicates this configuration would require significant transonic trim capability. This is a concern from the standpoint of the size requirements for the horizontal tails and/or body flaps to achieve this trim capability, and from the standpoint of the large trim drag penalty that will have to be incurred as a result of these control surface deflections.

\section{SUMMARY}

An experimental study was performed to examine jet-effects for an airframe-integrated, scramjet-rocket combined-cycle vehicle configuration at transonic test conditions. Concerns about jet-effects (in terms of both its prediction and the performance implications) during powered transonic flight provided the motivation for this investigation. To address these concerns, an existing exhaust simulation wind tunnel model, known as Model 5B, was tested in the NASA Langley 16-Ft. Transonic Tunnel. Test parameters were freestream Mach numbers from 0.7 to 1.2 , angles-of-attack from -2 to +14 degrees, and up to seven nozzle static pressure ratio values for a set of horizontal-tail and body-flap deflections. The model aftbody, wings, and body flaps were extensively pressure instrumented to provide an understanding of jet-effects and control surface/plume interactions, as well as for analytical methodology development and computational code calibration.

At all transonic test conditions examined, the exhaust flow at the exit of the internal nozzle was overexpanded, generating an exhaust plume that turned toward the aftbody. Pressure contour plots for the aftbody of Model 5B were presented for freestream transonic Mach numbers of 0.70, 0.95, and 1.20. These pressure data, along with shadowgraph images obtained, indicated the impingement of an internal plume shock and at least one reflected plume shock onto the aftbody for all transonic conditions tested. These results also indicated the highly threedimensional nature of the aftbody exhaust flowfield.

Test parameter sweeps were also performed and the results showed that: (1) increasing angle-of-attack above $2^{\circ}$ was shown to push the exhaust plume boundary closer to the aftbody, move the impingement location of the internal and reflected plume shocks farther upstream on the aftbody, and reduce the value of the peak pressures; (2) increased static nozzle pressure ratio increased the exhaust-jet plume size and shifted the impingement location of the internal and reflected plume shocks, as well as the peak pressures, farther downstream on the aftbody; and (3) variation of freestream Mach number greatly affected the aftbody pressure distributions. Integration of the pressure data for the Model 5B aftbody showed large variations in the pitching moment for the 0.7 to 1.2 Mach number range. This result indicates this configuration would require significant transonic trim capability.

Lastly, the jet-effect on the horizontal-tail lower surface was examined for 0-degree horizontal-tail deflections at $M_{\infty}=0.95$ as a function of SNPR for $\alpha=0^{\circ}$ and $\alpha=12^{\circ}$. No jet-effect on the horizontal tail was observed when the SNPR was increased from the minimum to maximum value. However, a slight jeteffect was present on the forward portion of the horizontal tails when comparing the jet-off to minimum jet-on conditions.

\section{ACKNOWLEDGEMENTS}

The authors acknowledge the support of NASA's NGLT program for provided the funding to perform this test. The authors also acknowledge the NASA Langley 16-Ft. Transonic Tunnel personnel for their dedicated support of this test. The technical support under the direction of the Test Engineers, James E. Byrd and Darlene C. Pokora, allowed the successful completion of the planned test matrix in a timely manner, and technical suggestions for performing the test and hardware modification and fabrication were greatly appreciated.

\section{REFERENCES}

1. Covault, C.: "Hypersonics Strategy Sets Stage for 'Next Great Step"', Aviation Week \& Space Technology, March 26, 2001, pp 28-29.

2. Capone, F. J.; Bangert, L. S.; Asbury, S. C.; Mills, C. T. L.; Bare, E. A.: "The NASA Langley 16-Foot Transonic Tunnel: Historical Overview, Facility Description, Calibration, Flow Characteristics, and Test Capabilities." NASA-TP-3521, Oct. 1995.

3. Huebner, L. D.: Computational Inlet-Fairing Effects and Plume Characterization on a Hypersonic Powered Model. Journal of Aircraft, vol. 32, no. 6, pp. 1240-1245, November-December 1995.

4. Witte, D. W.; Huebner, L. D.; Trexler, C. A.; Cabell, K. F.; and Andrews, E. H.: "Propulsion Airframe Integration Test Techniques for Hypersonic Airbreathing Configurations at NASA Langley Research Center." AIAA Paper 2003-4406, July 2003. 


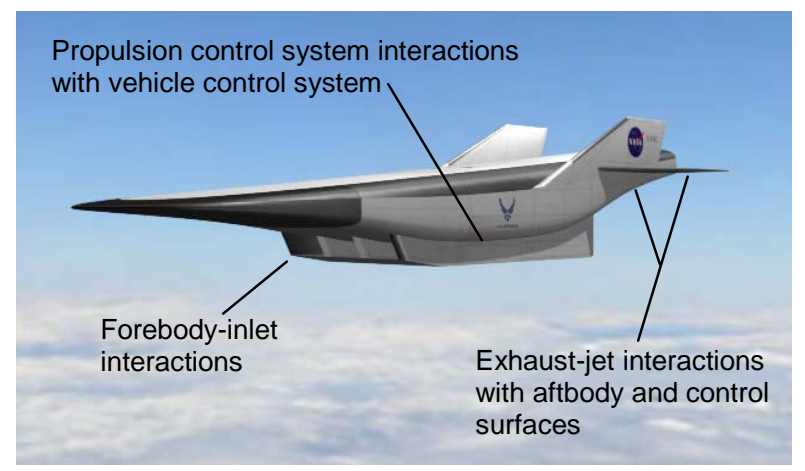

Fig. 1. Important PAI issues for an airframeintegrated scramjet vehicle.

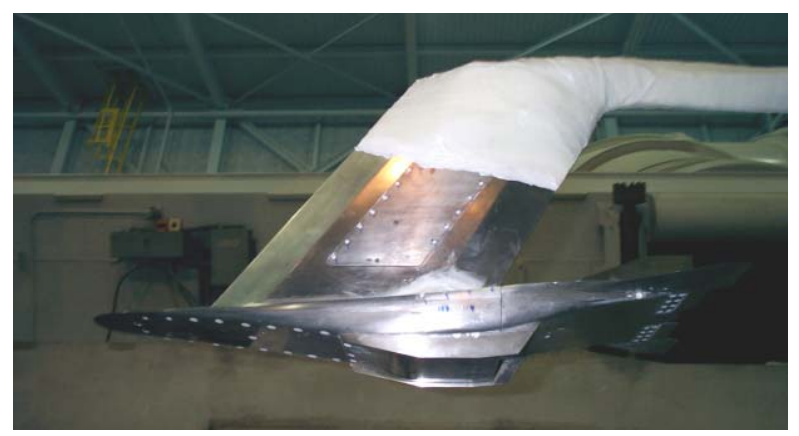

Fig. 2. Installation image of Model 5B in the NASA Langley 16-Ft. Transonic Tunnel.

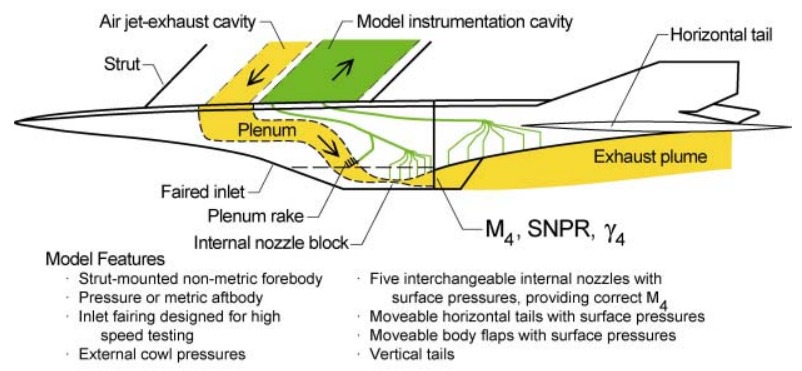

Fig. 3. Schematic illustration of Model 5B internal features used in 16-Ft. TT testing.

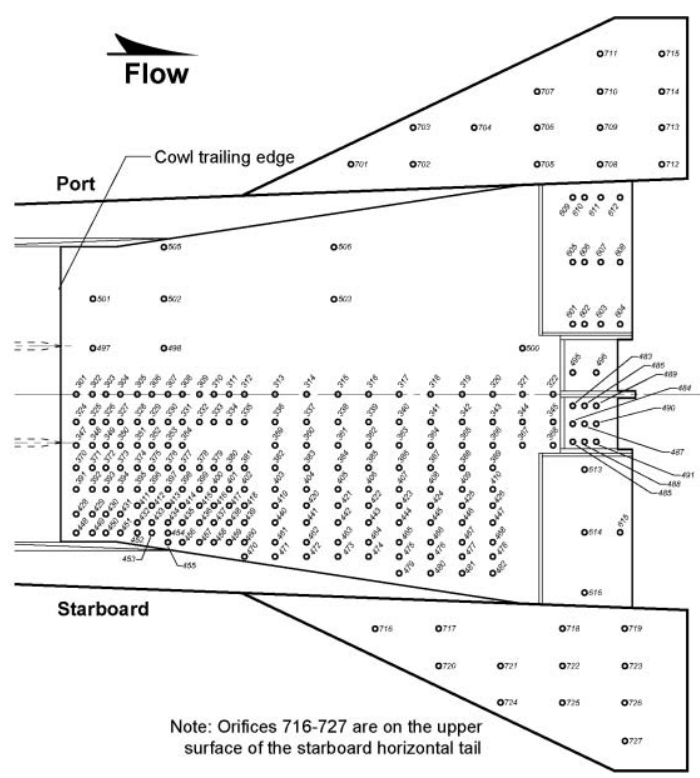

Fig. 4. Model 5B aftbody pressure instrumentation layout.

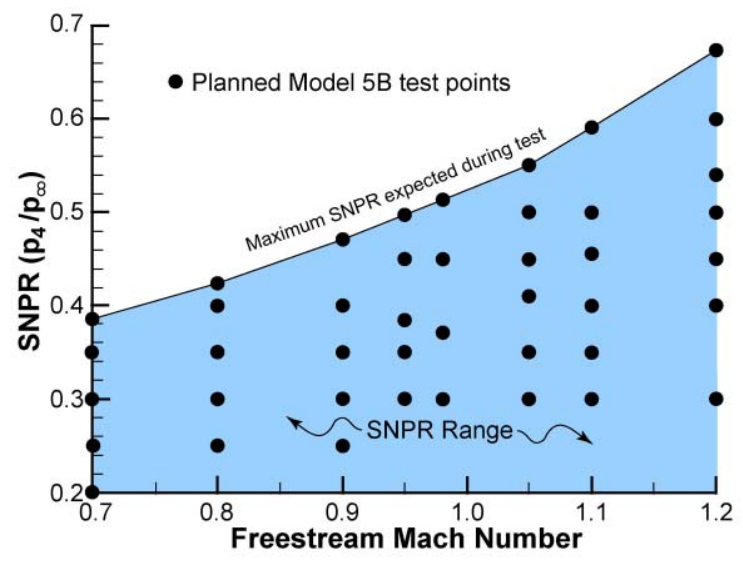

Fig. 5. Range of Model 5B static nozzle pressure ratios as a function of Mach number.

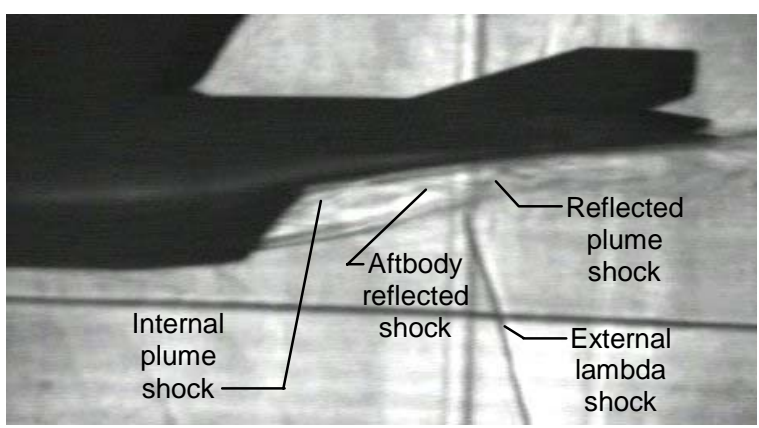

Fig. 6. Representative shadowgraph image exhibiting typical features of jet-exhaust flow. 


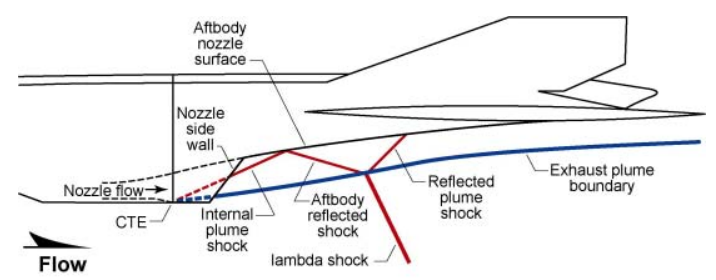

(a) Profile illustration showing location and cause of main pressure regions.

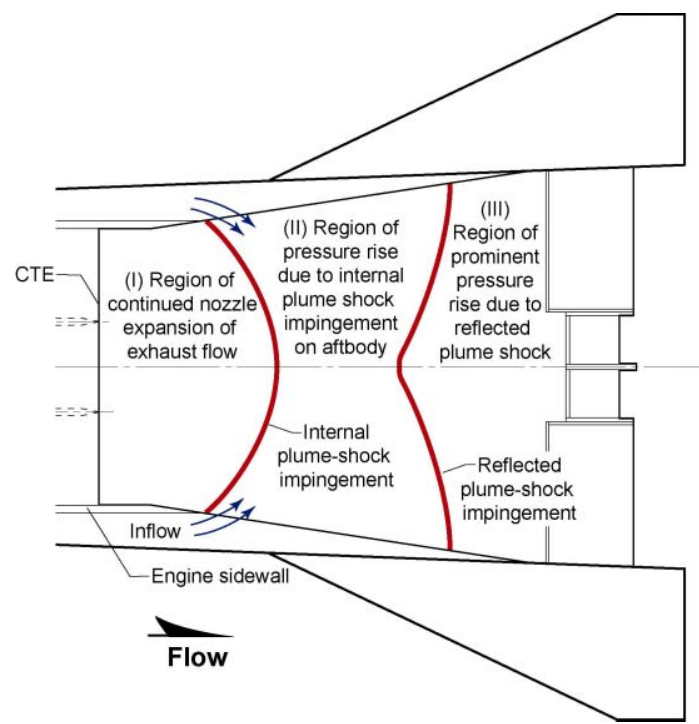

(b) Planform illustration showing location and cause of main pressure regions.

Fig. 7. Description of overexpanded exhaust-flow features at transonic test conditions.

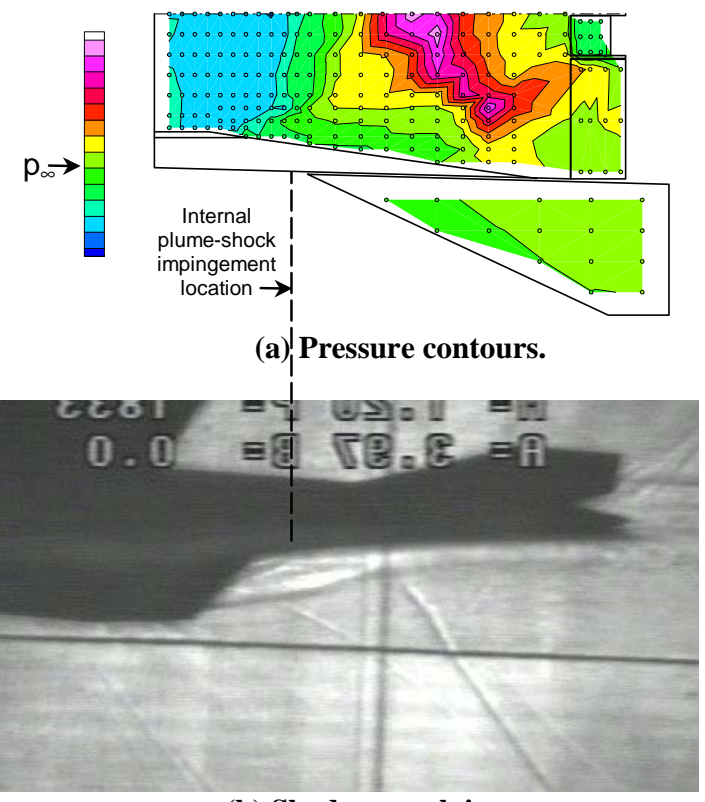

(b) Shadowgraph image.

Fig. 8. Aftbody exhaust-jet data, $M_{\infty}=1.2, \alpha=4^{\circ}$, SNPR=0.434.

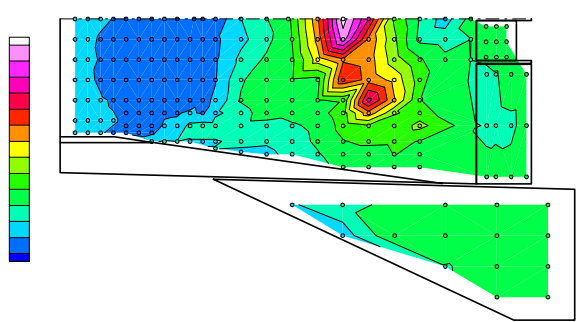

(a) Pressure contours.

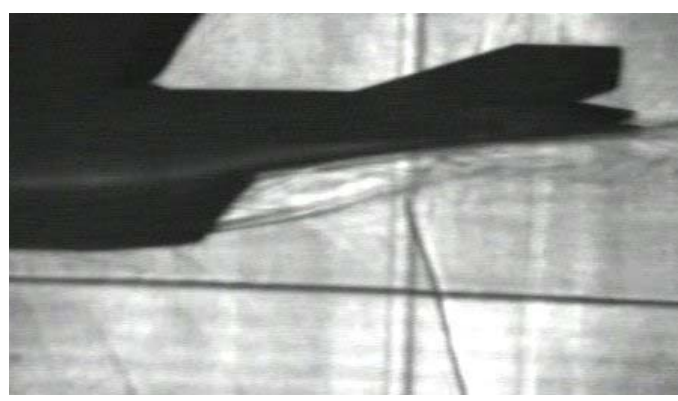

(b) Shadowgraph image.

Fig. 9. Aftbody exhaust-jet data, $M_{\infty}=0.95, \alpha=0^{\circ}$, SNPR=0.530.

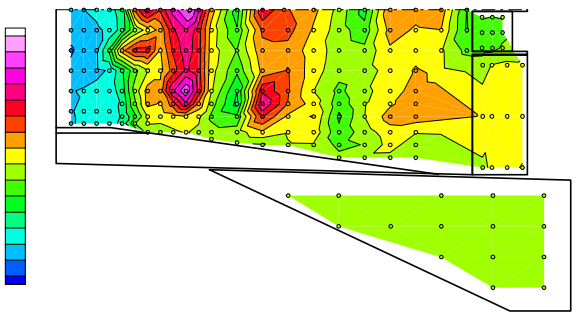

(a) Pressure contours.

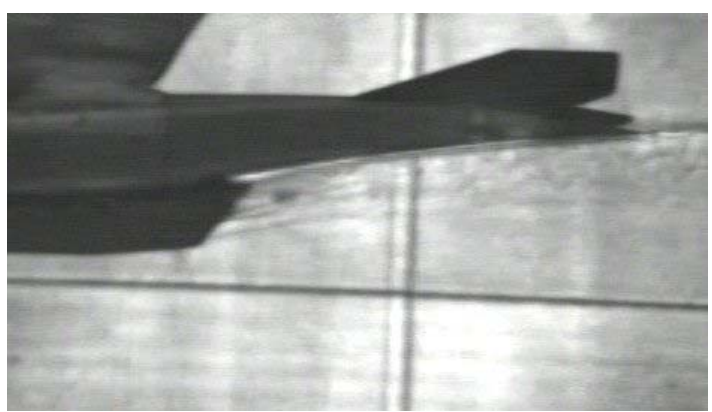

(b) Shadowgraph image.

Fig. 10. Aftbody exhaust-jet data, $M_{\infty}=0.7, \alpha=0^{\circ}$, SNPR=0.268. 


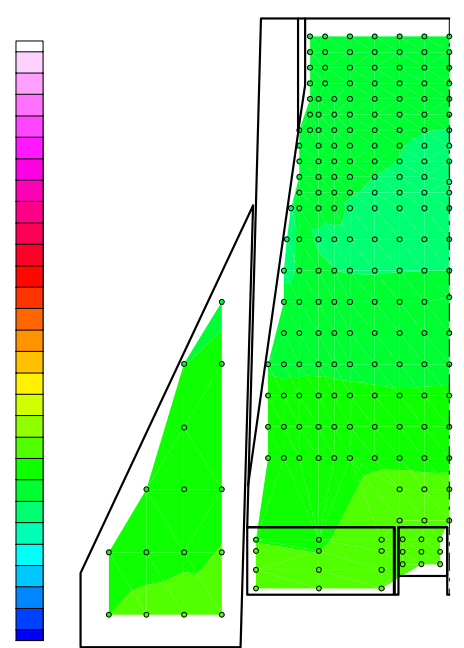

(a) No-jet condition.

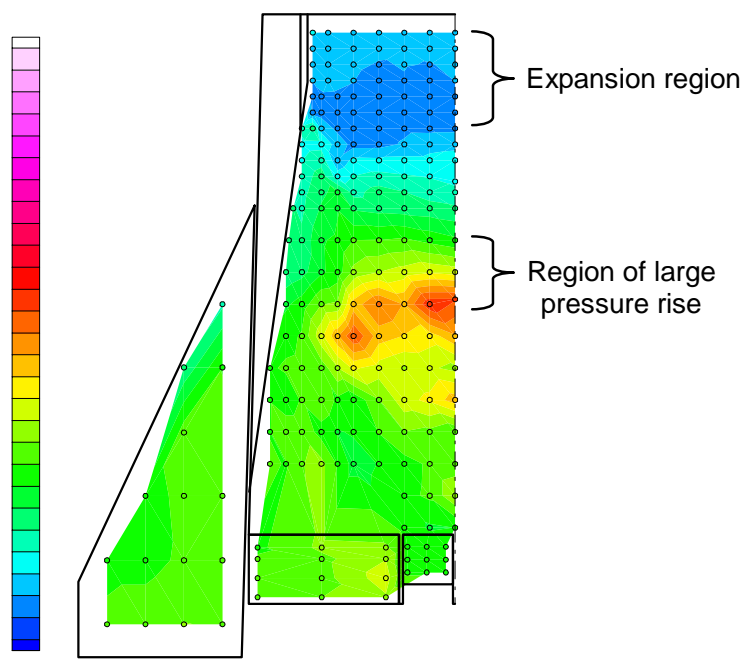

(c) $\mathrm{SNPR}=0.373$.

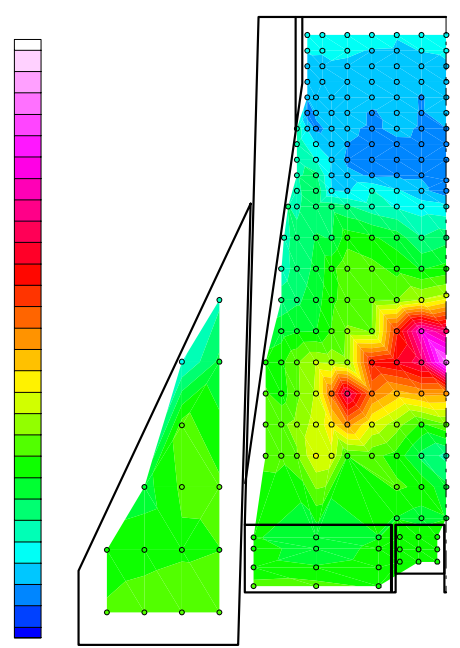

(e) $\mathrm{SNPR}=0.488$.

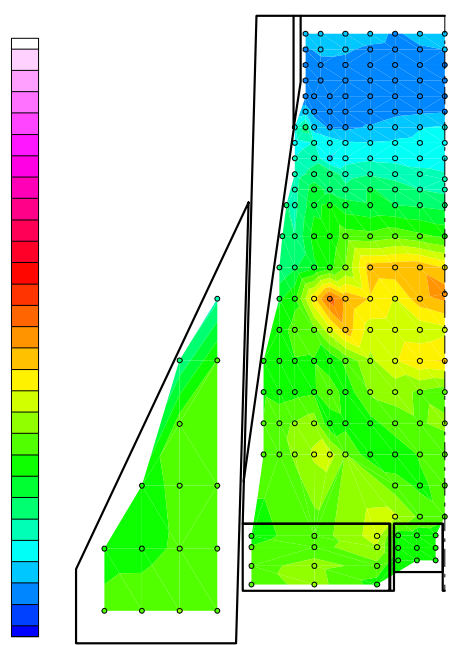

(b) $\mathrm{SNPR}=0.320$.

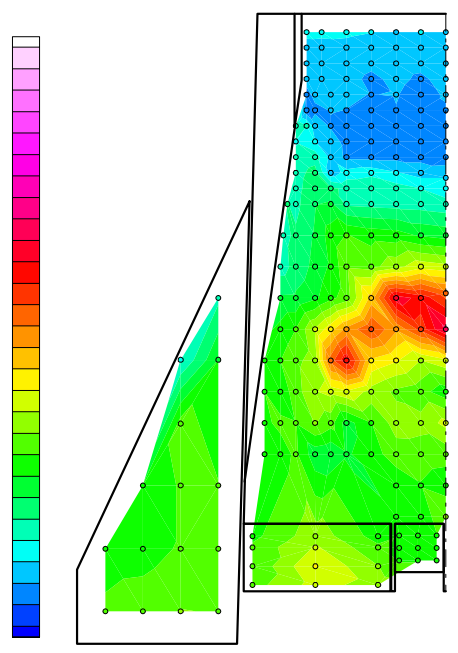

(d) $\mathrm{SNPR}=0.416$.

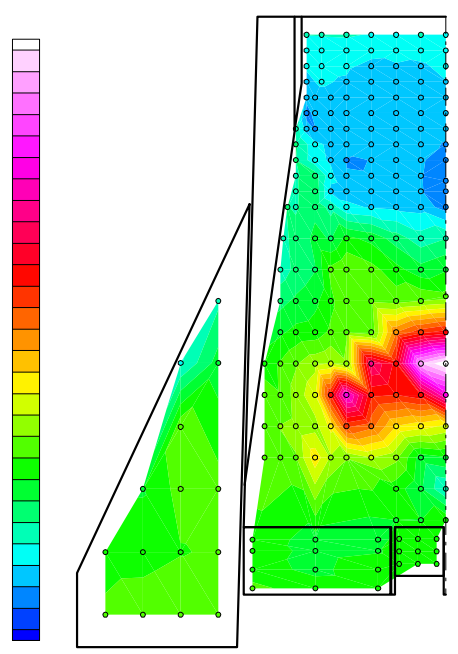

(f) $\mathrm{SNPR}=0.540$.

Fig. 11. Aftbody pressure-contour data, $M_{\infty}=0.95, \alpha=0^{\circ}$. 


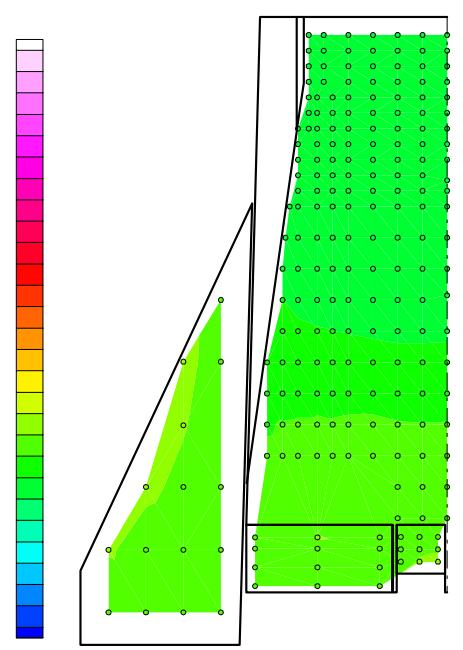

(a) No-jet condition.

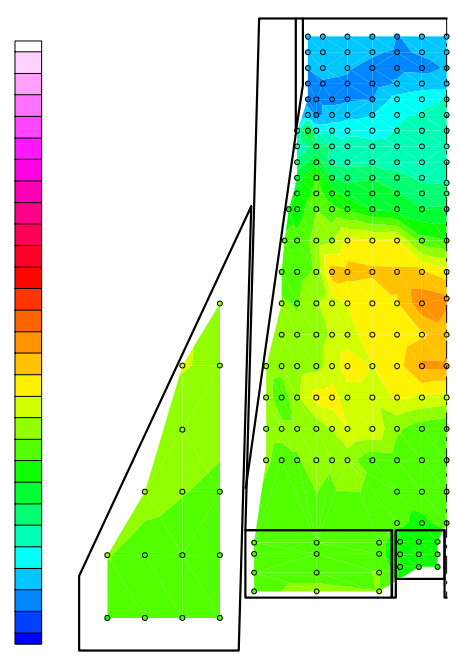

(c) $\mathrm{SNPR}=0.374$.

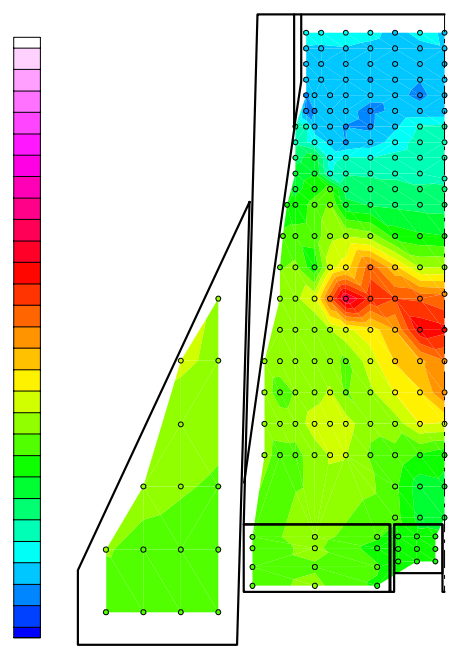

(e) $\mathrm{SNPR}=0.482$.

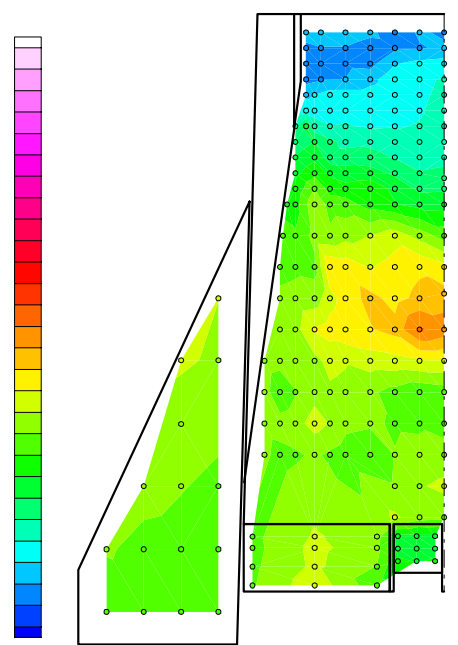

(b) SNPR = 0.324.

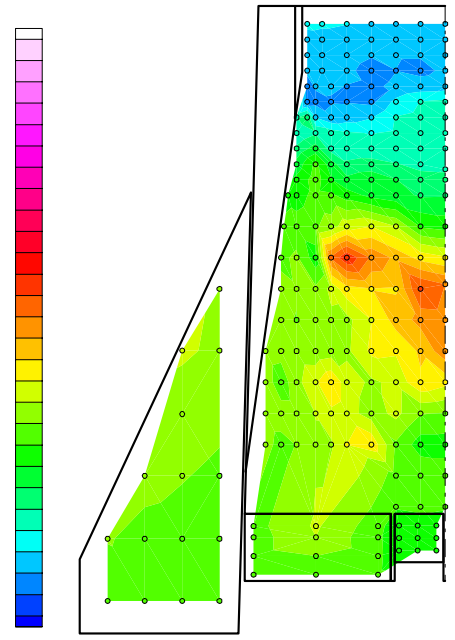

(d) $\mathrm{SNPR}=0.413$.

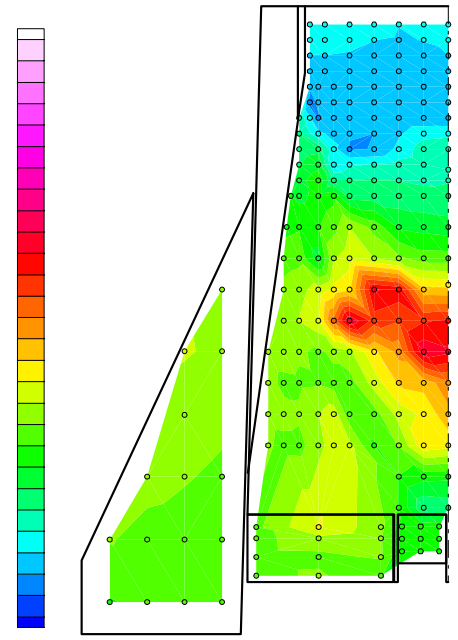

(f) $\mathrm{SNPR}=0.537$

Fig. 12. Aftbody pressure-contour data, $M_{\infty}=0.95, \alpha=12^{\circ}$. 


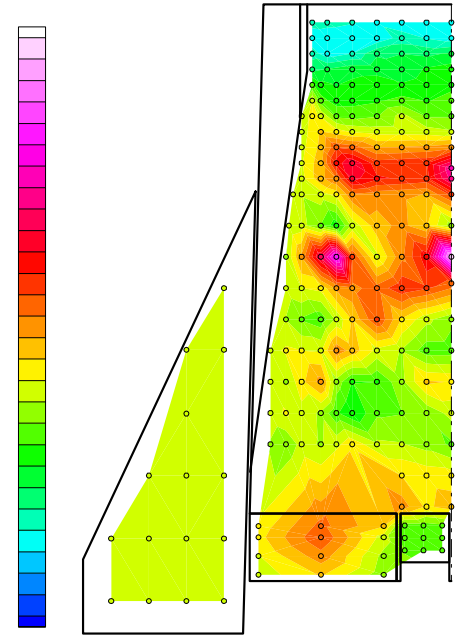

(a) $\mathrm{M}_{\infty}=\mathbf{0 . 7 0 ,}$ SNPR $=0.416$.

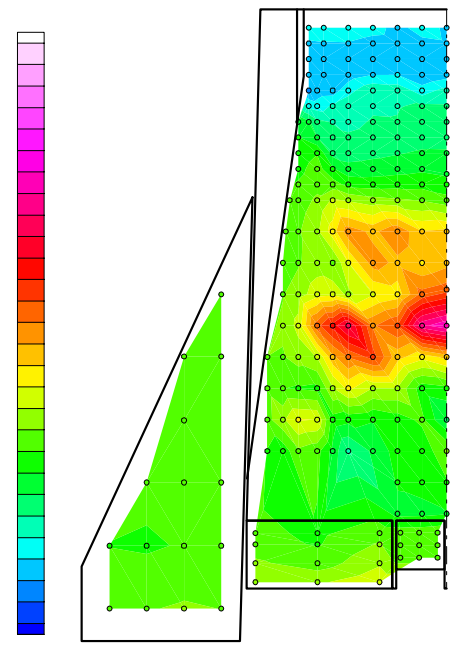

(c) $\mathrm{M}_{\infty}=0.90, \mathrm{SNPR}=0.427$.

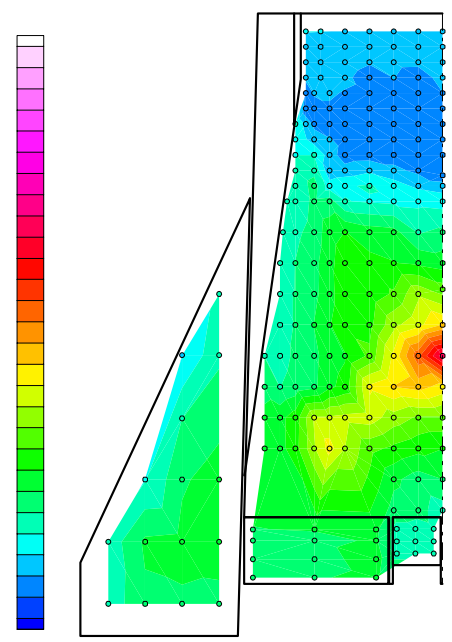

(e) $\mathrm{M}_{\infty}=1.10, \mathrm{SNPR}=0.493$.

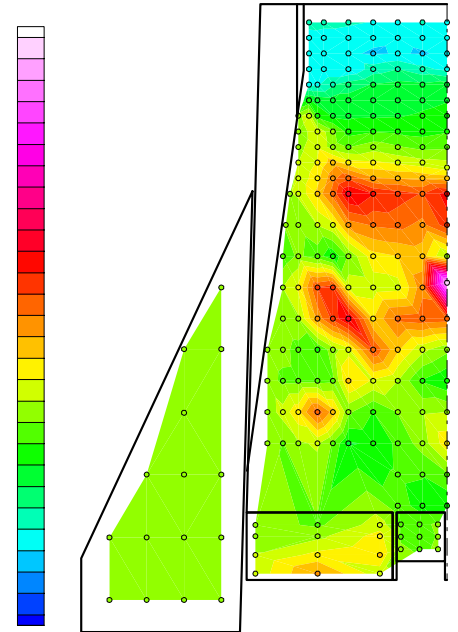

(b) $\mathrm{M}_{\infty}=\mathbf{0 . 8 0 ,}$ SNPR $=\mathbf{0 . 4 6 4}$.

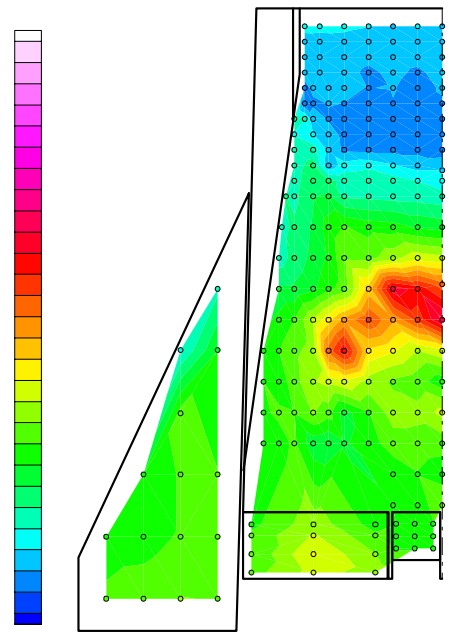

(d) $\mathrm{M}_{\infty}=\mathbf{0 . 9 5}, \mathrm{SNPR}=\mathbf{0 . 4 1 6}$.

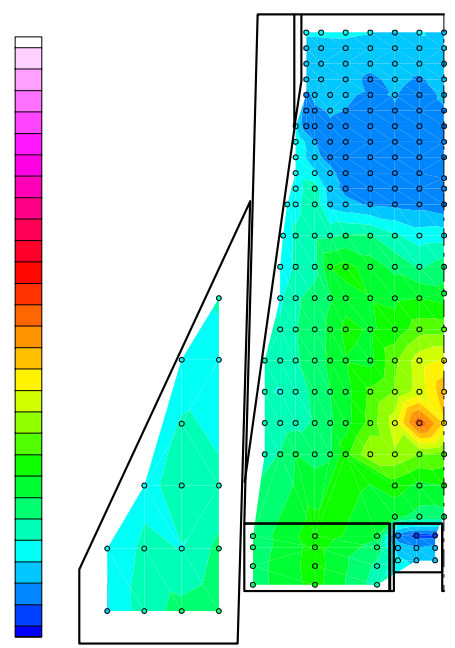

(f) $\mathrm{M}_{\infty}=1.20, \mathrm{SNPR}=0.572$.

Fig. 13. Aftbody pressure-contour data for a simulated transonic trajectory, $\alpha=0^{\circ}$. 


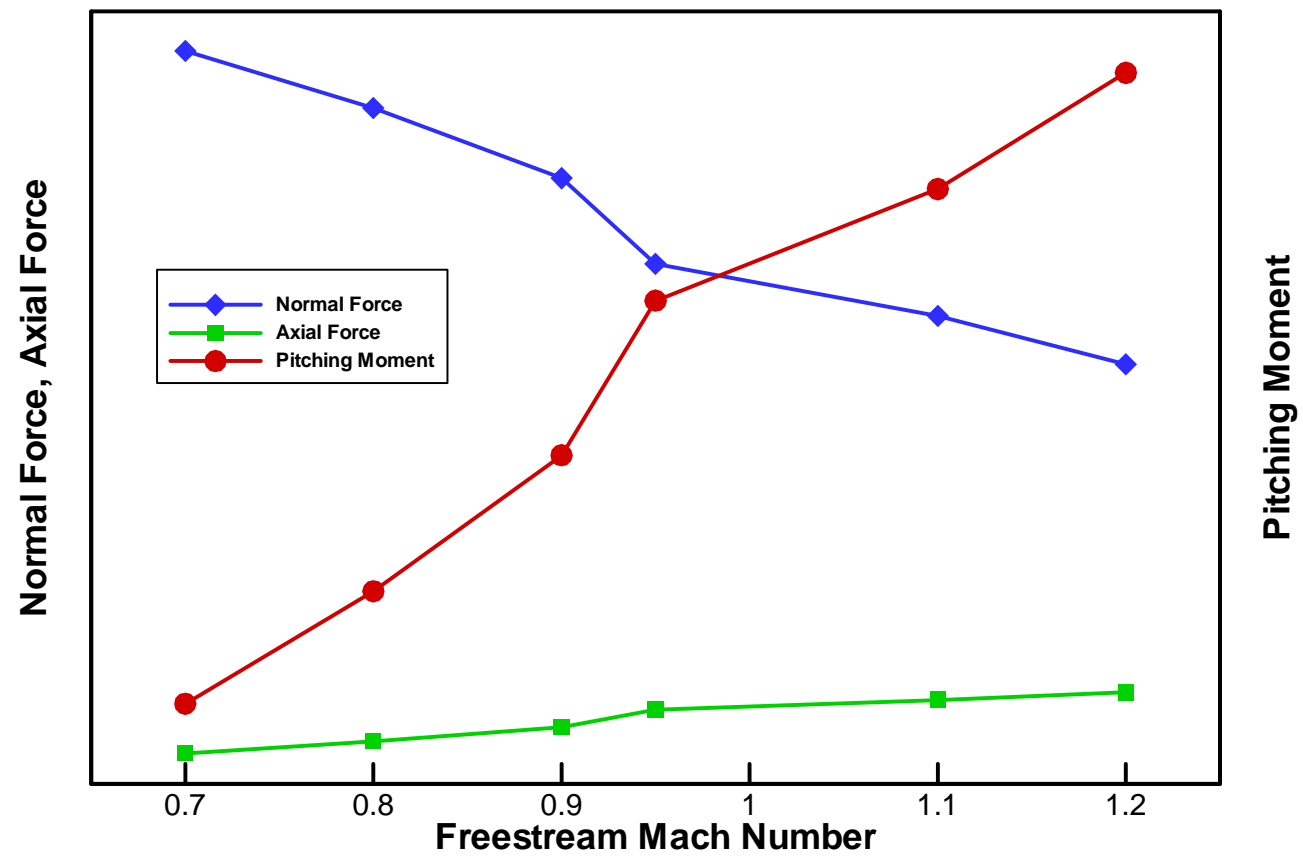

Fig. 14. Pressure-integrated, external-nozzle, force-and-moment results for the Model 5B aftbody through a simulated transonic flight path for the data presented in Figure 13. 